\title{
CONSUMING AUDIO: AN INTRODUCTION TO TWEAK THEORY
}

Audio technology is a medium for music, and when we pay attention to it we tend to speculate about its effects on the music it transmits. ${ }^{\text {. }}$ By now there are well-established traditions of commentary (many of them critical) about the impact of musical reproduction on musical production. Recording has commodified music, we are told, and driven a wedge between performer and audience. In popular music, multitrack recording dissolved the sense of group interaction; in classical music, audiences accustomed to the perfect accuracy of recordings demanded the same from live concerts, where interpretation consequently became cautious and stultified. Rock musicians, attempting to duplicate elaborate studio arrangements in concert performance, found themselves locked into synchrony with preprogrammed sequencers. And so on.

It is my purpose here neither to refine these arguments nor to refute them. Rather, I wish to change the subject slightly. I have nothing to say about technology as a medium for the producers of music; I will instead consider technology as part of the culture of the music audience. Audio technology, like other forms of technology, is not simply a tool used for a practical purpose, but bears cultural meanings and personal emotional investments. Furthermore, though it represents a realm of creative involvement and practical mastery for audio engineers, for most of its users it is something purchased, a commodity.

Scholars have already begun to study some of these aspects of music technology. Gay, for example, investigates the frameworks of meaning New York rock musicians use to make sense of their equipment. ${ }^{2}$ Théberge studies the commercial nexus within which musicians act as consumers of technology. ${ }^{3}$ There has also been a desultory tradition of reflection on the influence of music technology on the listener (notably Adorno on radio, ${ }^{4}$ Eisenberg on the record, ${ }^{5}$ Hosokawa on the Walkman ${ }^{6}$ ), but little of this work has focussed specifically on the listener as consumer of technology, and in any event most of it is cultural criticism rather than being ethnographically oriented.

The most convenient point of entry into the universe of meaning surrounding consumer audio equipment is surely the world of the audiophile, the person who takes audio very seriously indeed, investing large amounts of time and money in 
acquiring, using, and thinking about audio technology. Audiophilia is ideally suited for this investigation because of its complexity and visibility. It is a hobby, a form of 'serious leisure,' and a form of consumption; it provides its devotees with a source of self-images and an arena of social relationships, ranging from informal friendship networks, clubs, annual trade fairs and Internet discussion groups, to the 'community' of consumers of specialist audiophile magazines.

My topic, then, can be defined as the culture of audiophile consumption. In what follows I bring together my observations of audiophile life and thought with the findings of anthropologists, sociologists, and other scholars who have investigated the social meanings of consumption. I argue that in audio consumption, like consumption in general, the purchaser engages in appropriative work to turn the commodity into a possession. In the past, when audio technology was more mechanically-based, more modular, and more accessible to the user, such work could engage directly with the technical details of the product. As the technology became increasingly sealed off from the user, he - audiophiles are overwhelmingly male - responded with non-technical interventions. These 'tweaks', with no scientifically-accepted relationship to the technological principles of the audio device, continued to allow the user to appropriate, domesticate, and personalize store-bought equipment. However, they brought him into conflict with the technology's chief source of epistemic authority: audio engineering.

\section{The Audiophile}

The audiophile community cannot be sharply delineated; it shades off on one side into the great mass of casual consumers, and on the other into the professional coterie of engineers. Furthermore, it displays relatively little consensus of opinion; indeed, in some ways it is easier to define it by the topics it debates rather than the positions it unanimously affirms. For the purposes of this paper I will provisionally define the audiophile as someone interested in what the industry calls 'specialty' audio, what is usually marketed as 'the high end.'

In I994, Richard, a salesman in a specialty audio store, defined 'high end' for me as any system that costs $\$ 5000$ or more (others would no doubt draw the line elsewhere). In monetary terms, there is essentially no upper limit to the high end; it is possible to spend $\$$ I75,000 on a pair of speakers. Such extravagant products are probably more ogled-at than purchased even within the innermost circles of audiophilia, but in general it seems true that audiophiles, despite their small numbers, hold a relatively elite position in society and wield disproportionate economic power.

Audiophiles are mostly professional men, affluent and well-educated. In a survey conducted in I 988 by Stereophile magazine, of 9,000 respondants $47.4 \%$ had salaries above $\$ 50,000$; the average income reported was $\$ 58,900$. In a 
smaller I991 survey of 702 subscribers the average income was $\$ 80,700$. In the latter survey $55.8 \%$ of the responses reported household income above $\$ 50,000$, and $25 \%$ reported income above \$100,000. Of the I988 respondents, $80.6 \%$ had at least an undergraduate degree, and $57.2 \%$ worked in professional or technical fields. In both surveys, 99\% of the respondants were male.?

Audiophiles typically have extensive collections of recordings; in its I988 survey, Stereophile found its readers owned an average of $620 \mathrm{LP}$ 's and Io० CD's. Audiophiles follow one or more specialist periodicals, including Audio, Stereophile, and The Absolute Sound.

Although there are distinct schools of audiophilic thought, audiophiles distinguish themselves as a whole from the buyers of mass-marketed audio, the patrons of Circuit City, the readers of Stereo Review, whose homes are filled with 'rack systems' made by Japanese companies. All of these are subject to audiophilic scorn. The manufacturers are exposed to generic Japan-bashing; ${ }^{9}$ magazines like High Fidelity are accused of selling out to the companies that advertise in them; ${ }^{\text {Io }}$ and their customers and readers are characterized in more or less unflattering terms (e.g. 'comatose' ${ }^{\text {,II }}$ ).

Thus from one point of view the audiophile world is defined by equipment, and audiophiles set themselves apart from mass-market audio consumers through the esoteric commodities they buy, with brand names unknown to the average consumer (Krell, Thiel, B \& W, vAC, etc.) But many audiophiles are wary of defining themselves entirely in terms of mechanical and electronic devices. They are sensitive to the charge that they care only about expensive gadgets. They publicly present themselves as people who truly care about music, who take it much more seriously than the average person. Indeed, they commonly describe themselves as addicted to music. Listening becomes a passion: as one audiophile (I'll call him Jack) told me, he sometimes stays up all night listening to his records. Richard, the high-end audio salesman, said: 'Once you get bitten by the bug, that's the end. It's almost a disease - music is such an emotional involvement, it pushes so many buttons for people.'

\section{Audio and Consumption}

Regardless of the importance of audiophilia's technological and emotional aspects, audio is very much a realm of consumption, inhabited by a staggering variety of competing products. In I995 Audio magazine's annual directory listed 6222 models of equipment, including 3019 kinds of speakers, 818 kinds of amplifiers, 503 kinds of preamps, 358 kinds of headphones, I 68 kinds of phono cartridges, IIo kinds of turntables, I02 kinds of analog cassette decks, and 93 kinds of ambience/surround sound processors. To understand the nature of audiophilia, therefore, we need to understand some basic facts about the way commodities are consumed. 
Commodities awaiting sale are objects designed for consumption, depersonalized goods which belong to no one in particular. But pure commodities - permanently anonymous and perfectly interchangeable objects to which no personal identity or social meaning ever sticks - probably do not exist. Even money, supposedly an impersonal, undifferentiated medium defined entirely by its exchange-value, acquires personal and social meanings in people's lives. ${ }^{\text {I2 }}$ Commodities, too, absorb sentimental investments and social significance. People who buy commodities do not merely gain ownership over them in exchange for cash; they appropriate them through rituals of acquisition and display. Appadurai therefore prefers to speak of commodity situations rather than commodities, situations into and out of which objects can move throughout their life cycles. ${ }^{\text {I3 }}$

The social and cultural import of the commodity was famously argued by Mary Douglas and Baron Isherwood in their I979 study, The World of Goods. 'Commodities are good for thinking,' they insisted, borrowing Lévi-Strauss's famous phrase; consumers use goods to make 'visible and stable the categories of culture'. ${ }^{14}$ Consumption also provides a medium for social interaction:

'Enjoyment of physical consumption is only a part of the service yielded by goods; the other part is the enjoyment of sharing names. (...) Take football, or cricket: the fan internalizes a reel of his names inside his head. He knows the famous victories, infamous losses, and draws; he loves to talk about historic games, good referees, vast crowds, inspiring captains, good years and bad, the present and the old days. Inside him are grades of passionate judgement. Another enthusiast need only utter two words to betray the vast amount of sharing that is possible for them both. These joys of sharing names are the rewards of a long investment of time and attention and also of cash'. ${ }^{\text {I5 }}$

What sorts of meanings do commodities acquire? We can broadly categorize them as social and personal, corresponding to two approaches in the study of consumption.

The first - indebted to the work of Veblen and Bourdieu - traces the meanings of objects to the social strata with which they are associated. ${ }^{16}$ The other approach - associated with the names of Mauss, Kopytoff, and Carrier - looks at the private uses of objects, the ways they lend meaning to, and draw meaning from, personal relationships. ${ }^{\text {I7 }}$

I will deal here only briefly with the social meanings of audio equipment. As is clear from the survey results reported above, high-end audio is closely associated with demographic variables such as socio-economic status and gender. The readers of Stereophile belong disproportionately to the higher income brackets, and they are relatively well-educated, thus ranking high on the scales of both economic and cultural capital. (Of course, not all readers of audiophile magazines can afford to spend tens of thousands of dollars on audio equipment. Many of 
them participate in the high-end world by buying second-hand equipment at a steep discount, some assemble their own electronics, and some are purely spectators, reading the audiophile press and hanging out at audio salons without ever making a purchase. The audiophile press functions for the latter group as the purveyor of a fantasy world, but it is still a high-status world of economic power.)

The gender connotations of audiophilia are equally evident: audiophiles are overwhelmingly male. This is unsurprising, given the historic identification of engineering in general with men, and audio technology's specific associations with masculinity over the past several decades. ${ }^{18}$

For my present purposes, however, the audiophile's personal relationship with the equipment is of more interest. By expending energy in the process of acquisition, by modifying the object acquired, and by means of rituals of display, the audiophile can personalize the commodity he buys; he can, that is, appropriate it.

Appropriation is the work of imprinting the identity of the owner on the thing owned, converting an anonymous commodity into a personal possession. ${ }^{\text {I9 }}$ Appropriation can involve physical or symbolic alteration of the object. The work of appropriation can be promoted by special consumption spaces that 'provide a coherent identity for much of what is bought and sold in them'. ${ }^{20}$ It is also furthered by a personal relationship between seller and buyer. ${ }^{2 \mathrm{I}}$

Another way commodities are appropriated is through the buyer's exercise of choice. Some consumers invest a great deal of work in choosing what to buy. When this effort is directed at discovering the best price or value, and avoiding the seductions of advertisers, impulse buying, and so on, we may call it rational consumption. This kind of consumption is a way of investing the buyer's identiy into the act of shopping, and hence into the commodities purchased. ${ }^{22}$ (Strictly speaking, however, it injects the commodity with a certain aspect of the shopper's identity: his or her identity as the careful, rational agent, in control of him or herself, keeping utility always in view, immune to the blandishments of fashion, peer pressure, or even convenience.)

These facets of appropriative work are all evident in audiophilia. High-end audio boutiques or 'audio salons' provide special consumption spaces. Audiophiles often develop long-term relationships with a salesperson at such stores. Indeed, some audiophiles make personal contact with the manufacturers of their equipment. Jack was proud of the fact that his pre-amp was made by two men in a shop in West Virginia, and he could get on the phone to them whenever he wanted.

The type of appropriation I wish to focus on here, however, is the physical modification of the equipment, for it is through this sort of work that the audiophile most obviously invests himself in his equipment. There is a term for this in audiophilia; it is called tweaking. 


\section{Tweaking}

Jay was one of the system engineers at the campus computer center. I noticed a cartoon from an audiophile magazine on his door when I went to apply for an E-mail account, and struck up a conversation. He told me he liked The Absolute Sound better than Stereophile, which he thought was less critical of the components it reviews. He admired Harry Pearson, editor of The Absolute Sound, because he was one of the first people who refused to accept engineers' claims about audio equipment, and trusted his ears instead.

Jay then told me about a little experiment he tried with his equipment. He had been reading about a company that makes small ebony discs which, when attached to audio components, improve the sound. The reviewer tried them on some high-end speakers and was amazed at the difference. Jay wanted to try it on his own speakers, but since they weren't as expensive as the ones the reviewer used, he thought he might not need fancy ebony discs, so he taped pennies on to the sides of the speaker cones. It made a difference! Jay was listening to a saxophone concerto (he used to play sax), and the pennies let him hear the sound of the reed. They improved the definition, they made it sound like there was a real instrument there, not like a watercolor. He couldn't understand how it could work. He didn't know all the physics of it. All he could imagine was that the wood sides of the speakers vibrate sympathetically at some frequency, and the pennies damp it. Though how thick, braced wood can be vibrating, he had no idea. If Jay told some engineer about this, he'd say Jay was on drugs!

Tweaking is modifying purchased equipment; a tweak is 'any small, fussy thing that improves the sound of an audio system'. ${ }^{23}$ The term is not unique to the audio world; it is applied to computers, cars, and bicycles as well, as any search of magazine indexes will reveal. It has, however, taken some remarkable manifestations in the audiophile community, and plays a special role in the conceptual universe of audiophilia. Tweaking audio equipment is an act of devotion to sound, a demonstration of one's willingness to 'labor in its service'. ${ }^{24}$ The personal effort involved makes tweaking a way of investing the equipment with one's self, that is, a process of appropriation.

The recent prominence of tweaking is due in part to the historical shift from phonograph-based to $\mathrm{CD}$-based audio systems. These technologies differ greatly in the scope they allow for consumer appropriation. The phonograph lent itself especially well to user modifications, since it had several mechanicallyseparable parts (stylus, cartridge, tonearm) and adjustable operating parameters (such as tracking force, anti-skating, cartridge alignment, and vertical tracking angle). Records and styli could be tended in various ways: dusted with special brushes, lubricated with special fluids, cleaned with special cleaners. 
Electronic components, lacking such mechanical interfaces, do not demand, or even allow, such simple but conspicuous demonstrations of the user's solicitude. However, in earlier decades at least, such components could be assembled by the consumer. When building an amplifier from a kit, there is no clear line of distinction between the act of acquisition and the act of tweaking: one simply modifies the unit during or after assembly, as many do-it-yourselfers did with their Dynaco kits. ${ }^{25}$ Some store-bought units were susceptible to similar kinds of modification; for example, in the I970s many audiophiles added ribbon tweeters to their speaker systems. ${ }^{26}$

However, a different way of tweaking electronic components such as amplifiers and preamps eventually emerged (apparently in the late I970s), one which involved minimal or no technical skills or knowledge. Some of these used easily-available materials, some required specially-marketed devices, but most were inert, non-electronic (indeed, non-mechanical): for example, placing bricks or bags of sand on top of components, or insulating mats or rubber feet under them. ${ }^{27}$

The introduction of the $\mathrm{CD}$ eliminated the scope for user adjustment permitted by the LP: 'the closed nature of digital systems seems to prohibit the tinkering and finicky adjustment which make analog such involving fun.' The CD seemed to deprive the buyer of 'the thrill of custom-tailoring' his system, since he could no longer mix and match turntables, tonearms, and cartridges. ${ }^{28}$ For some audiophiles, digital's untweakability was a reason to avoid the format. ${ }^{29}$ Others embraced the $\mathrm{CD}$, but found new, non-technical tweaks to apply to it. Consequently, the formerly obscure category of the non-technical tweak increased sharply in visibility..$^{\circ}$

A great variety of such tweaks proliferated: applying magic marker to the edge of CD's, or rubber rings to their upper surface; spraying them with Armor All, or putting them in the freezer. New tweaks for other components continually emerged: placing small bits of foil on the electronic parts of a CD player or amplifier (to counteract the adverse effects of 'gravitational energy'), resting speakers on tennis balls, and so on. ${ }^{3 \mathrm{I}}$

Tweaks like these, involving cheap, readily available materials, require no sophisticated industrial laboratories or million-dollar research budgets, and their use preserves the consumer's autonomy. However, manufacturers soon recognized in tweaking a market they could exploit, and started producing tweaking devices - some of them quite costly - such as eight-pound metal blocks encased in oak, to be placed over power transformers $;^{32}$ electrical units to demagnetize a CD before playing it; ${ }^{33}$ vibration-damping and isolation devices ('platforms, stands, weights, bases, and feet $\left.{ }^{34}\right)$; and devices to 'tune' a room or a component.

As an example of the latter, consider the Shun Mook 'resonance-control' devices. (These 'Mpingo Discs' are the type of product that inspired Jay's experiment with pennies, described above.) Made of ebony, about one and one-half 
inches in diameter and one-half inch thick, they cost $\$ 50$ each. They can be applied to turntables, CD players, or preamps. (Other 'tuning' devices are meant to be applied to speaker cabinets.) They were devised by Dr. Yu Wah Tan, who gave the following rationale for his decision to make them from African ebony:

'... most fine instruments, like the cello or double bass, use ebony in the finger boards. The right resonance! Resonance is energy, so you can't eliminate it, you can only transform it'.

As Scull explains,

'The basic idea is to preserve and tune these resonances rather than damage the sound by trying to eliminate them.(...) Good resonances are like the ones in a violin (...) Bad resonances are the mechanical ones found in preamps, for instance, that are outside the musical spectrum.(...) [T] he Shun Mook products attempt to preserve the 'good' resonances and evacuate harsh, mechanical, non-musical resonances $(. . .)^{35}$

\section{Tweaks and the Contest for Epistemic Authority}

The effectiveness of such tweaks is controversial, and many audio engineers (as well as the self-described 'sensible' or 'rational' audiophiles) hold them up to derision. Some argue that, devoid of either 'solid theory' or 'empirical evidence,' tweaks like these merely 'cater to the vanity of the audiophile. ${ }^{36}$ Indeed, when subjected to engineering tests they routinely fail. For example, in March I990 the International $\mathrm{CD}$ Exchange newsletter recommended that $\mathrm{CD}$ owners paint the edges of their disks with green magic marker to improve the sound. An engineer, David Ranada, decided to test this tweak. He digitally measured the output of treated versus untreated disks, and found no change. Hans Fantel, a New York Times' audio reviewer, then spread the word that this tweak was ineffective and even dangerous. ${ }^{37}$

These pronouncements in the name of science do not silence the tweakers, however. They respond in various ways, chief among them by appealling to the ear. The defenders of these tweaks privilege the evidence of their own senses over the findings of the officially-accredited authorities on technology, with their elaborate equipment:

'The proponents of the various tweaks are not claiming that the improvements will show up in measurements. Yet every music lover I know has heard the differences. Obviously, there are improvements as well as degradations in digital sound that aren't measurable. Digital has its unsolved mysteries'.$^{38}$ 
As this quotation shows, awarding ultimate authority to the ear means limiting the authority of scientific knowledge; it means accepting the presence of mystery in human hearing or in audio equipment. Indeed, the manufacturers of tweaks sometimes use the inexplicability of their devices as a promotional resource. The following advertising copy shows how Shun Mook sells the Mpingo discs by emphasizing their resistance to rational explanation:

'We invite you to place a Shun Mook spatial control kit consisting of 9 Mpingo Discs on any system in our store and experience a musical miracle. You will hear cleaner highs, richer harmonics, a more holographic sound stage and tighter bass. While your mind will not deny the experience you will hear, it will have trouble understanding just how 9 small discs that measure only I. 75 " by 0.5 " created this dramatic improvement. It's enough to drive anyone bananas! We know, because we're still trying to figure it out'. ${ }^{39}$

The critics of tweaking are not convinced by these arguments. They neither find the appeal to the ear conclusive, nor admit that current scientific knowledge is powerless to account for these phenomena. They typically dismiss the 'audible improvements' as due to placebo effects - they believe audiophiles think they hear improvements where none exist because they feel they should be able to. To distinguish truly audible differences from imaginary ones, standard engineering methodology employs double-blind comparison tests. These tests typically show that most people who claim to hear differences cannot do so under controlled conditions. ${ }^{40}$

Defenders of tweaks respond in various ways. It is possible, for example, to admit that the audible improvements in sound they produce are due to placebo effects, but to argue that, from the point of view of the user, placebo effects are as real as any other sort of effect:

'Belief and perception are two mutually dependent interactive variables they feed and influence each other (...) If a baseball player believes that not washing his 'lucky socks' will improve his batting average, then it will (...) The power of an audiophile's degaussed and cryogenically treated CD is just as real as the ballplayer's lucky socks, and just as dependent on his belief to work its wonders'. ${ }^{4}$

It is also possible to dismiss the incompatibility between these devices and scientific theory by noting that science - Western science - is only one belief system among many. Using science to judge the products of other belief systems is ethnocentric:

'Shun Mook's products are being summarily rejected because the belief system they're based in is different from traditional Western thought. This isn't 
fair. Until we become familiar enough with the belief system in which they were developed to have a "feel" for what they can or cannot do, we cannot really evaluate them'. ${ }^{42}$

\section{Conclusion}

The evolution of audio technology has thus turned the appropriative gesture of the tweak into an occasion for epistemic controversy. The tweak debate is only one instance of a general pattern of contestation of authority in the world of audio. There are similar arguments over the merits of tube versus transistor amplifiers, single-ended versus push-pull circuit designs, LP versus CD, $96 \mathrm{kHz}$ versus 44.IkHz sampling rates, and over esoteric cables. All of these debates pit the findings of audio engineering against the evidence of audiophile ears; in the case of the LP and single-ended circuits, the ear-friendly technology is also the one which gives greater scope for the consumer's hands-on activity.

This pattern of controversy is not peculiar to audio technology, but is in its turn an example of a more general phenomenon. As historians have shown, the introduction of new consumer technologies often builds new arenas for competition over authority. For example, the early spread of electrical technologies in America brought with it new institutions to distinguish those truly entitled to technological authority from those who merely claimed it. ${ }^{43}$ The audio debates are notable in this context because they do not counterpose one set of experts against another, but against a universal human capacity - hearing.

Privileging the evidence of the ear over engineering measurements is, I suggest, conceptually congruent with the appropriative impulse of tweaking. In both cases, the average consumer is empowered in the face of the institutions of industrial technology. A moment's work with a felt-tipped marker pen can reclaim audio technology from the factory; faith in one's own hearing wrests authority from the highly-trained expert. In such ways does the personalizing gesture of tweaking find support, and an echo, in the epistemic realm.

\section{Notes}

I. This essay develops some of the themes of a larger research project on audiophilia. I wish to thank Robert Lancefield for originally alerting me to the existence of the audiophilia debates, and to René Lysloff for encouraging me to present my interim findings at the I994 meetings of the Society for Ethnomusicology. I am grateful to 'Richard,' 'Jack,' and 'Jay,' for welcoming me into their homes, offices, or stores; to Susan Smulyan for some enlightening discussions on the history of technology; to Peter Kulchyski, Dominic LaCapra, and Susan Buck-Morss for their perceptive criticisms; and to Trevor Pinch, Bruno Latour, and Luc Boltanski for their reassuring enthusiasm. I alone, however, am responsible for the interpretations offered herein.

This essay is also published in: R.T.A. Lysloff \& L.C. Gay (eds) Music and Technoculture, Wesleyan University Press, Middletown, Connecticut 2003, p. 346-357. (Permission granted by Wesleyan u P.) 
2. L. Gay, 'Acting Up, Talking Tech', in: Ethnomusicology, 42, I, I988, p. 8I-98.

3. P. Théberge, Any Sound You Can Imagine: Making Music/Consuming Technology, Hanover I997.

4. T. Adorno, 'A Social Critique of Radio Music', in: Kenyon Review, 8, 2, I945, p. 208-2I7.

5. E. Eisenberg, The Recording Angel, London 1988.

6. S. Hosokawa, 'The Walkman Effect', in: Popular Music, 4, I984, p. I65-180.

7. J. Atkinson, 'Stereophile and You', in: Stereophile, II, I0, I988, p. 69-77; Id., 'Who Are You?', in: Stereophile, I5, 6, 1992, p. 7-10.

8. The reported predominance of analog recordings is in part attributable to the age of these collections and the novelty of CD's (introduced in I983), and in part to the explicit refusal of $20 \%$ of the respondents to buy digital recordings (Atkinson, 'Stereophile and you', I988). In the I99I survey, only $39.2 \%$ of the respondents reported buying LP's in the past twelve months, compared with $93 \%$ who purchased CD's (Atkinson, 'Who are you?', I992).

9. J. O'Connell, 'The Fine-Tuning of a Golden Ear: High-End Audio and the Evolutionary Model of Technology', in: Technology and Culture, 33, I992, p. I-37; 22.

Io. H. Pearson, 'Viewpoints', in: Absolute Sound, I, I, I973, p. 4-6; 4.

II. W. Parsons, 'In the Digital Quicksand', in: Absolute Sound, I9, 93, I994, p. 26-27; 27.

I2. V. Zelizer, The Social Meaning of Money, Princeton 1997.

I3. A. Appadurai (ed.), The Social Life of Things, Cambridge I986, p. I3.

I4. M. Douglas \& B. Isherwood, The World of Goods. With a new introduction, London 1996 [1979], p. 4I, 38.

I5. Ibid., p. 5 I.

I6. J. Carrier, 'Reconciling commodities and personal relations in industrial society', in: Theory and Society, I9, I990, p. 579-598; 579 .

I7. Ibid., p. 58r.

I8. K. Keightley, “Turn it down!' she shrieked: gender, domestic space, and high fidelity, I948-59', in: Popular Music, I5, 2, I996, p. I49-I77.

I9. Carrier, 'Reconciling commodities and personal relations in industrial society', p. 583.

2o. Ibid., p. 583 .

2I. Ibid., p. 588 .

22. Ibid., p. 586 .

23. D. Denby, 'Twin Tweaks', in: New York, 23, 27, I6 July I990, p. 44-45; 44.

24. E. Rothstein, 'The quest for perfect sound', in: New Republic, I93, 30 December I985, p. $29 \mathrm{ff}$.

25. R. Hodges, 'David Hafler and Audio Civilization', in: Stereo Review, 94, March 1985.

26. A. Lofft, 'Sense and Nonsense in High-End Hi-Fi', in: Stereo Review, 47, Io, October 1982, p. $62-69 ; 65$.

27. Ibid., p. 65-66.

28. I. Berger, 'Philosophies to Count On', in: Audio, 69, II, Nov. I985, p. 8-Io.

29. S. Tellig, 'The Audio Anarchist', in: Stereophile, I3, 5, I990, p. 62-67; 62

30. Denby, 'Twin Tweaks'.

3I. K. Kessler, 'Industry Update', in: Stereophile, I4, I, I99I, p. 53-57.

32. Brick, 'The vPI Brick', in: Stereophile, 5, 4, I982, p. I3-I4, 30.

33. J. Scull, 'Four Tweaks and a Freebie', in: Stereophile, 19, 2, 1996, p. 177-183.

34. M. Colloms, 'Harmonix Tuning Devices by Combak', in: Stereophile, I6, 7, I993, p. I3I-40; I3I.

35. J. Scull, 'Shun Mook Resonance-control Devices', in: Stereophile, I7, 2, I994, p. II9-I25; II9.

36. The critic goes on to offer his own interpretation of the significance of tweaking: "That is, after all, the nature of tweaking. It is saying, "I can improve this multikilobuck equipment by using this cheap little fix". Here we see one way the proponents of rational consumption make sense of the activity of appropriation: they can attribute it to moral weakness ('vanity') on the part of the consumer.'

37. H. Fantel, 'Brush aside the idea of painting CD’s', in: New York Times, $\$ 2,3$ June I990, p. 26. 
38. Denby, 'Twin Tweaks'.

39. This advertisement appeared in The Absolute Sound, volume I9, number 93, p. I67.

40. O'Connell, 'The Fine-Tuning of a Golden Ear', p. I4.

4I. B. Willis, 'The Art of Scientific Illusion', in: Stereophile, I7, 5, I994, p. 49-5I; 49.

42. Ibid., p. 5I.

43. C. Marvin, When Old Technologies Were New, New York I988, p. 4I. 